\title{
e-interview
}

\section{Brian Lawlor}

Brian Lawlor is Professor of Old Age Psychiatry at Trinity College and St James's Hospital, Dublin. He trained at the University of Florida and the National Institute of Mental Health (NIMH), Bethesda, Maryland. Special interests include Alzheimer's disease and later-life depression.

If you were not a psychiatrist, what would you do?

I would be involved in tennis coaching or teaching.

What has been the greatest impact of your profession on you personally? Realising that I am not as nice a person as I thought I was before I entered psychiatry.

Do you feel stigmatised by your profession?

Not by my profession; sometimes by my professional colleagues.

What are your interests outside of work?

Tennis, cycling, music, theatre, art.

Who was your most influential trainer, and why?

DrTrey Sunderland. He taught me critica evaluation skills and promoted my selfbelief.

What job gave you the most useful training experience?

Medical Staff Fellow at NIMH.

Which publication has influenced you most?

Erich Fromm's The Art of Loving.

What research publication has had the greatest influence on your work? Pope \& Lipinski (1978) Diagnosis in schizophrenia and manic-depressive illness: a reassessment of the specificity of 'schizophrenic' symptoms in light of current research. Journal of Geriatric Psychiatry, 35, 811-828.

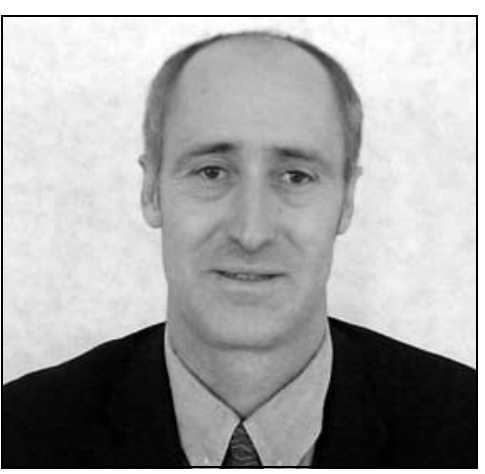

What part of your work gives you the most satisfaction?

Teaching and patient contact (but not in the extreme)

What do you least enjoy?

Management.

What is the most promising opportunity facing the profession?

The increasing importance of mental health to quality of life and the currency that this will generate for the profession.

What is the greatest threat? Deskilling by focusing only on psychotic disorders and severe mental illness.

What single change would substantially improve quality of care? There is no single or simple change that can improve life. That's a fact of life.

What conflict of interest do you encounter most of ten?

Distinguishing between my needs and the patient's needs.

Do you think psychiatry is brainless or mindless?

I think psychiatry needs leadership but that is not a brain or mind issue.

How would you entice more medical students into the profession?

We need to get to young minds before they become medical students. The minds of many medical students are already too weary for conversion.
What is the most important advice you could offer to a new trainee? Revised laws of the House of God - the patient is not the only one with that disease. Get to know your patient but first get to know yourself

What are the main ethical problems that psychiatrists will face in the future?

Breaching confidentiality. End of life decisions/suicide.

How would you improve clinical psychiatric training? Lessen clinical pressures on both trainer and trainee.

What single change to mental health legislation would you like to see? Not so much the legislation as improving the administration of the Act (Mental Health Act 1983) in the best interest of the patient and the clinical management of services.

How should the role of national bodies such as the Royal College of Psychiatrists/American Psychiatric Association change?

Such institutions need to become more relevant to all psychiatrists in their day to day practice.

What is the future for psychotherapy in psychiatry training and practice? Bleak, unless embraced by trainees and trainers.

What single area of psychiatric research should be given priority? Fostering the importance of research in practice.

What single area of psychiatric practice is most in need of development? Incorporating personality and non-psychotic disorders into mainstream psychiatric practice.

Dominic Fannon

doi: $10.1192 /$ pb.bp.107.018820 